\title{
Pengaruh Penggunaan Social Media Terhadap Brand Awareness Pada Objek Wisata Di Kota Batam
}

\author{
Debby Arisandi ${ }^{1 *}$, Mohamad Nugraha Reza Pradana ${ }^{2}$ \\ International University Liaison Indonesia, Universitas Universal \\ *Korespondensi: debby.arisandi@iuli.ac.id
}

\begin{abstract}
Abstrak
Kota Batam merupakan kota industri yang kemudian beralih menjadi kota pariwisata. Kontribusi sektor pariwisata terhadap PAD kota Batam untuk tahun 2015 sebesar $17,56 \%$. Namun demikian, keterbatasan program promosi yang dilakukan menyebabkan masih banyak masyarakat yang masih belum mengetahui adanya objek-objek wisata pantai yang dikelola masyarakat tersebut. Penelitian ini bertujuan untuk menunjukkan manfaat penggunaan beberapa media sosial yang terdiri dari variabel Youtobe, Facebook, Instagram, Twitter terhadap Brand Awareness. Penelitian ini berjenis kuantitatif, dengan melibatkan 384 orang responden yang diambil secara acak sebagai sampel penelitian. Data yang digunakan adalah data primer yang diperoleh melalui alatbantu kuisioner. Alat analisa menggunakan Regresi Linear Berganda. Dari hasil penelitian menunjukkan bahwa media sosial (youtube, Facebook, Instagram, dan Twitter) berpengaruh secara signifikan terhadap Brand Awareness dan sangat penting dalam meningkatkan kesadaran merek pariwisata berbasis swadaya masyarakat. Hasil Penelitian juga menunjukkan bahwa penggunaan media sosial terbukti berpengaruh signifikan terhadap pemasaran obyek wisata di kota Batam. Akan tetapi, hal ini belum dimanfaatkan secara maksimal, terbukti baru 3 dari 19 kawasan wisata yang sudah memanfaatkan media sosial untuk mendukung program promosinya. Karena itu, perlu dukungan dari berbagai pihak yang terkait untuk mendukung promosi obyek wisata di Kota Batam.
\end{abstract}

Kata Kunci : social media, brand awareness, wisata batam

\begin{abstract}
Batam City is an industrial city which later turned into a tourism city. The contribution of the tourism sector to Batam's PAD for 2015 was 17.56\%. However, the limitations of the promotion program carried out caused many people who were still unaware of the coastal tourism objects managed by the community. This study aims to show the benefits of using several social media consisting of Youtobe, Facebook, Instagram, Twitter variables on Brand Awareness. This research is a quantitative type, involving 384 respondents taken randomly as a research sample. The data used are primary data obtained through questionnaires. Analyzer uses Multiple Linear Regression. The results of the study show that social media (youtube, Facebook, Instagram, and Twitter) have a significant influence on Brand Awareness and are very important in increasing awareness of community-based tourism brands. The results of the study also showed that the use of social media proved to have a significant effect on tourism marketing in the city of Batam. However, this has not been fully utilized, proven only 3 out of 19 tourist areas that have used social media to support their promotional programs. Therefore, support from various parties involved is needed to support the promotion of tourism objects in Batam City.
\end{abstract}

Keywords: social media, brand awareness, batam tourism

\section{A. PENDAHULUAN}

Batam adalah salah satu pulau yang berada diantara perairan selat Malaka dan selat Singapura. Pada awalnya Batam dikembangkan sebagai kota industri dan sektor alih kapal. Sektor pariwisata di Batam mulai dilirik pada tahun 2008. Sektor pariwisata dikembangkan dan diambil alih oleh Dinas Pariwisata dan Kebudayaan Kota Batam. Struktur perekonomian kota Batam di dominasi oleh sektor industri (kontribusinya 
sekitar 60\%) dan berorientasi ekspor (lebih dari $80 \%$ nilai ekspor berasal dari komoditi produk industri). Dengan demikian, upaya meningkatkan jumlah wisatawan manca negara yang berkunjung ke kota Batam dapat diikuti dengan peningkatan besarnya pengeluaran yang dilakukan selama berkunjung. Hal ini akan berdampak pada penerimaan devisa non migas dan perkembangan sektor-sektor ekonomi terkait, sehingga memberikan dampak positif terhadap pertumbuhan ekonomi kota Batam.

Tingginya kunjungan wisatawan ke Kota Batam, sangat berpengaruh besar terhadap sektor penerimaan (PAD) kota Batam, yakni dari segi hotel, restoran, dan hiburan. Menurut Dinas Pariwisata dan Kebudayaan Kota Batam, Kontribusi sektor pariwisata terhadap PAD kota Batam untuk tahun 2015 sebesar 17,56\%.

Tabel 1 : Persentase Tingkat penghunian kamar pada hotel berbintang di daerah tujuan wisata

Kepulauan Riau (\%) pada Desember 2016

\begin{tabular}{ll}
\hline Jenis Hotel & Persentase (\%) Penghunian Kamar Hotel \\
\hline \hline Bintang 4 & 53,45 \\
\hline Bintang 3 & 58,28 \\
\hline Bintang 2 & 42,81 \\
\hline Bintang 1 & 43,92 \\
\hline Seluruhnya & 49,61 \\
\hline Sumber : (BPS Kota Batam, 2015)
\end{tabular}

Tingkat penghunian kamar hotel ialah banyaknya malam kamar yang dihuni dibagi dengan banyaknya malam kamar yang tersedia dikalikan 100 persen.

Tabel 2 : Jumlah wisatawan asing yang datang melalui Bandara Hang Nadim, Batam

\begin{tabular}{cr}
\hline Tahun & Jumlah Wisatawan Asing \\
\hline $\mathbf{2 0 1 1}$ & 1.161 .581 \\
\hline $\mathbf{2 0 1 2}$ & 1.219 .608 \\
\hline $\mathbf{2 0 1 3}$ & 1.336 .430 \\
\hline $\mathbf{2 0 1 4}$ & 1.454 .110 \\
\hline $\mathbf{2 0 1 5}$ & 1.443 .955 \\
\hline $\mathbf{2 0 1 6}$ & 1.432 .472 \\
\hline $\mathbf{2 0 1 7}$ & 1.418 .495 \\
\hline Sumber : (BPS Kota Batam, 2017) \\
\hline
\end{tabular}

Tamu Asing adalah setiap pengunjung yang mengunjungi suatu negara di luar tempat tinggalnya, didorong oleh suatu atau beberapa keperluan tanpa bermaksud memperoleh penghasilan di tempat yang dikunjungi. Definisi ini mengacu pada definisi yang dipakai World Tourism Organization, (WTO). Wisatawan mancanegara (wisman) yang datang melalui pintu masuk utama Bandara Hang Nadim, Batam pada 2016 berjumlah 1.432 .472 orang. Jumlah ini mengalami penurunan dari wisman yang masuk pada tahun sebelumnya yang berjumlah 1.545 .818 orang. Dengan adanya penurunan ini, maka mengakibatkan penurunan pendapatan dari sektor pariwisata.

Data yang dilansir oleh We are Social (Social, 2017), sebuah agensi digital marketing di Amerika, menyebutkan bahwa platform media sosial yang paling banyak digunakan di Indonesia per Januari 2017 adalah Youtube (49\%) dan oleh Facebook (48\%). Posisi selanjutnya ditempati oleh Instagram (39\%), Twitter (38\%), Whatsapp (38\%), dan Google (36\%). Sisanya ditempati secara berurutan oleh FB Messenger, Line, Linkedin, BBM, Pinterest, dan Wechat. 
Banyak objek wisata yang terdapat di Kota Batam. Sebagai kota kepulauan maka orientasi wisata yang berada di kota Batam lebih didominasi oleh wisata bahari. Selain itu kota Batam juga dikenal sebagai wisata Belanja dikarenakan lokasinya yang bertetangga dengan Singapura sehingga banyak barang-barang branded dari Singapura yang masuk ke Batam dengan harga yang lebih murah apabila dibeli di Jakarta. Objek wisata bahari di Kota Batam masih banyak yang dikelola secara swadaya oleh masyarakat. Berikut ini adalah objek wisata pantai yang terdata oleh Dinas Pariwisata Kota Batam sampai tahun 2015.

Tabel 3 : Objek Wisata Pantai

\begin{tabular}{clll}
\hline No. & \multicolumn{1}{c}{ Objek Wisata Pantai } & \\
\hline \hline 1. & Tanjung Memban & Kel. Batu Besar, Kec. Nongsa \\
\hline 2. & Kampung Melayu & Kel. Batu Besar, Kec. Nongsa \\
\hline 3. & Nongsa & Kel. Sambu, Kec. Nongsa \\
\hline 4. & Teluk Mata Ikan & Kel. Sambu, Kec. Nongsa \\
\hline 5. & Batu Besar & Kel. Batu Besar, Kec. Nongsa \\
\hline 6. & Melayu & Kel. Rempangcate, Kec. Galang \\
\hline 7. & Melur & Kel. Sijantung, Kec. Galang \\
\hline 8. & Pulau Abang & Kel. Pulau Abang, Kec. Galang \\
\hline 9. & Pulau Hantu & Kel. Pulau Abang, Kec. Galang \\
\hline 10. & Pulau Rano & Kel. Pulau Abang, Kec. Galang \\
\hline 11. & Pulau Karas & Kel. Karas, Kec. Galang \\
\hline 12. & Permata Subangmas & Kel. Subangmas, Kec. Galang \\
\hline 13. & Mirota & Kec. Galang \\
\hline 14. & Setokok & Kel. Setokok, Kec. Bulang \\
\hline 15. & Melawa & Kel. Sekanakraya, Kec. Blk. Padang \\
\hline 16. & Tanjung Pingir & Kel. Tanjungpinggir, Kec. Sekupang \\
\hline 17. & Tanjung Datuk & Kel. Tanjungpinggir, Kec. Sekupang \\
\hline 18. & Tanjung Buntung & Kel. Bengkonglaut, Kec. Bengkong \\
\hline 19. & Pasir Putih & Kel. Kampung Bagan (Tanjung Piayu) Kec. Sei Beduk \\
\hline & Sumber : (Disbudpar Kota Batam, 2016)
\end{tabular}

Kebanyakan objek wisata pantai diatas masih dikelola oleh masyarakat melalui koordinasi Lembaga Pemberdayaan Masyarakat Desa (LPMD). Pengelolaan secara swadaya masyarakat ini mengakibatkan program promosi yang dilakukan sangat terbatas dikarenakan dana penjualan tiket masuk hanya sebatas untuk operasional kebersihan dan keamanan lingkungan saja, tidak seperti objek wisata yang dikelola oleh instansi swasta seperti kawasan wisata Mega Wisata Ocarina di Batam Center yang dengan dukungan dana yang sangat kuat mampu membangun sarana dan prasarana pantai yang lengkap dan bagus sekaligus mengelola program promosinya secara professional. Akibat keterbatasan program promosi dari objek wisata pantai yang dikelola masyarakat ini menyebabkan masih banyak masyarakat khususnya di wilayah Batam saja yang masih belum mengetahui adanya objek-objek wisata pantai yang dikelola masyarakat tersebut.

Latar belakang tersebut mendorong untuk melakukan penelitian guna mencari tahu pengaruh penggunaan media sosial terhadap kesadaran merk wisata pantai yang dikelola secara swadaya oleh masyarakat. Tentunya semakin banyak pengguna media 
sosial yang mengetahui akan adanya objek wisata pantai akan mendorong mereka untuk berkunjung ke lokasi sehingga efek lanjutannya akan meningkatkan kesejahteraan masyarakat di sekitar objek wisata tersebut.

\section{B. TINJAUAN PUSTAKA}

Media Sosial yaitu sebuah kelompok aplikasi berbasis internet yang dibangun berdasarkan fondasi ideologis dan teknologi dari web 2.0, yang memungkinkan terjadinya penciptaan dan pertukaran konten yang diciptakan oleh penggunanya (Hays et al., 2013).

Sosial merujuk pada strategi komunikasi atau cara orang berinteraksi. Kemudian media merupakan alat komunikasi atau cara orang berinteraksi. Media juga dapat diartikan sebagai alat komunikasi seperti televisi, koran atau radio. Sosial media adalah komunikasi 2 (dua) arah melalui tulisan, foto, video maupun audio yang disalurkan melalui internet (Constantinos Iacovou, 2016). Media sosial merupakan bentuk nyata dari media baru (new media) berbasis kemajuan teknologi komunikasi yang didukung oleh teknologi informasi (Information and Communication Technology). Media sosial dipahami sebagai bentuk baru komunikasi di internet yang ditopang oleh berbagai aplikasi software, yang memungkinkan terjadinya interaksi di antara para pengguna. Media sosial memiliki beberapa kelebihan, terutama pada kemampuannya dalam komunikasi dua arah yang interaktif, dan memudahkan penggunanya untuk mengakses berbagai macam informasi tanpa hambatan dan jarak. Di dalamnya sangat dimungkinkan terjadi interaksi sosial, baik antar individu, individu dengan kelompok, bahkan individu dan kelompok dengan massal.

Beberapa situs media sosial yang populer pada saat ini adalah facebook, twitter, dan youtube. Ketiganya masih akan menguasai dunia media sosial hingga dua tahun ke depan. Pengguna Facebook di Indonesia per November 2016 mencapai 54\% dari pengguna internet. Angka berikutnya diikuti Instagram sebesar $15 \%$ dan posisi selanjutnya ditempati oleh Youtube (11\%), Google Plus (6\%), Twitter (5.5\%), dan Linkedin (0,6\%). (APJII, 2016)

Aspek penting dari media sosial adalah proses interaksi yang berada pada jalur maya, yang menjadi bagian dari budaya massal. Kehadiran media sosial mampu menghilangkan batas ruang dan waktu, yang selama ini menajdi pembatas dalam berinteraksi bagi mereka yang berada pada tempat yang berjauhan. Bagi perkembangan komunikasi pemasaran, media sosial memungkinkan peningkatan nilai (value) dari para pelakunya, dengan menggunakan prinsip membangun relasi antara perusahaan dengan follower atau fans. Nilai yang dimaksud yaitu bagaimana setelah jalinan antara kedua belah pihak pelaku media sosial terwujud, terdapat dampak positif yang tidak hanya berdampak pada satu pihak saja, namun juga merambah pada cakupan yang lebih luas. Daya bidik media sosial terhadap pencitraan perusahaan maupun brand, bahkan mampu menurunkan biaya kampanye yang biasanya dilakukan secara konvensional oleh perusahaan.

Berdasarkan peraturan Walikota Batam Nomor 61 tahun 2012 tentang Uraian Tugas Pokok dan Fungsi Dinas Daerah Batam bahwa Dinas Pariwisata dan Kebudayaan mempunyai tugas melaksanakan urusan pemerintahan daerah di bidang Kepariwisataan dan Kebudayaan, serta melaksanakan tugas-tugas lain yang diberikan Walikota sesuai dengan lingkup tugas dan fungsinya. Sesuai dengan kedudukan, tugas dan fungsinya Dinas Pariwisata dan Kebudayaan kota Batam menetapkan visi yaitu: 
"Terwujudnya Batam sebagai Kawasan Pengembangan Budaya Bangsa dan menjadi Pintu Gerbang Pariwisata Indonesia Bagian Barat".

Kesadaran merek secara luas disalahpahami dan sering salah diukur, bahkan oleh manajer berpengalaman. Namun Kesadaran Merek tercakup di sebagian besar teks pada pengukuran iklan yang merupakan bagian sentral dari model iklan hirarki efek yang populer, dan manajer pemasaran mengklaimnya sebagai tujuan penting dari kegiatan komunikasi mereka.

Kesadaran Merek digunakan untuk mengukur keefektifan dan menyelidiki berapa banyak target yang memiliki pengetahuan sebelumnya tentang merek yang diukur dengan pengenalan merek dan ingatan merek. Pengenalan merek mengukur sejauh mana merek diingat ketika namanya diminta, pengingat merek mengacu pada pelanggan yang dapat mengingat merek tertentu ketika diberi kategori produk tanpa menyebutkan nama apa pun dalam kategori.

Kesadaran merek sangat penting untuk proses komunikasi terjadi karena mendahului semua langkah lain dalam proses pemasaran. Tanpa kesadaran merek terjadi, tidak ada efek komunikasi lain yang dapat terjadi. Agar konsumen membeli merek, mereka harus terlebih dahulu disadarkan. Sikap merek tidak dapat dilakukan dan perhatian untuk membeli tidak dapat terjadi kecuali kesadaran merek telah terjadi. (Arisandi, 2017)

Dalam teori memori, kesadaran merek diposisikan sebagai langkah pertama yang vital dalam membangun "bundel" asosiasi yang melekat pada merek dalam memori. Merek adalah konsep dari jaringan asosiasi merek dalam memori, dengan merek sebagai inti utama telah dikemukakan oleh banyak orang lain. (Stokes, 1985)

Ada dua jenis kesadaran merek: kesadaran merek dan ingatan merek, dan yang mana hal ini terjadi akan tergantung pada situasi pilihan. Kesadaran merek tidak perlu memerlukan penarikan nama merek. Konsumen dapat mengidentifikasi merek berdasarkan lokasi atau kemasan atau bentuknya. Selain itu, penarikan kembali merek mungkin tidak diperlukan untuk pembelian, lebih banyak pengenalan merek di toko. Jelas, pengenalan merek terjadi dalam situasi berbasis stimulus, dan ingatan terjadi dalam situasi berbasis memori. Kedua jenis kesadaran ini akan terjadi dalam situasi campuran.(Rossiter \& Percy, 1987)

Tujuan utama dari kebanyakan bisnis adalah untuk meningkatkan penjualan dan pendapatan. Idealnya yaitu ingin menarik pelanggan baru ke produk dan mendorong pembelian berulang. Kesadaran merek mengacu pada bagaimana menyadari pelanggan dan pelanggan potensial.

Maka berdasarkan paparan yang telah disampaikan diatas, maka hipotesis yang diangkat pada penelitian ini adalah: Diduga, ada pengaruh yang positif dan signifikan dari variabel media sosial yaitu Youtobe, Facebook, Twitter dan Instagram, terhadap brand awareness pariwisata kota Batam

\section{METODE PENELITIAN}

Penelitian ini adalah penelitian kuantitatif. Metode penelitian kuantitatif merupakan metode penelitian yang berlandaskan pada filsafat positivisme, digunakan untuk meneliti pada populasi atau sampel tertentu (Sugiyono, 2012). Penelitian kuantitatif dipilih sebagai metode penelitian utama untuk mengklasifikasikan penelitian ini, mengukur dan menganalisis bagaimana otoritas Dinas Pariwisata Kota Batam memanfaatkan media sosial untuk mengajak dan mengikutsertakan keterlibatan 
konsumen dengan tujuan pasar. Analisis kuantitatif dipilih untuk digabungkan sebanyak mungkin data dan ruang lingkup aktivitas media sosial.

Populasi pada penelitian ini yaitu jumlah penduduk di kota Batam. Berdasarkan data dari BPS (Badan Pusat Statistik) Kota Batam, jumlah penduduk kota Batam pada tahun 2016, yaitu 1.236.399 jiwa. (BPS Kota Batam, 2017b). Dalam menentukan sampel pada penelitian ini, peneliti menggunakan sampel Krejcie dan Morgan. Berdasarkan jumlah populasi tersebut, maka jumlah sampel yang akan digunakan adalah 384 sampel.

Teknik pengambilan sampel pada penelitian ini dilakukan secara random dan menggunakan instrumen penelitian. Simple random sampling digunakan untuk pengambilan sampel dari pupulasi yang dilakukan secara acak, tanpa memperhatikan strata yang ada dalam populasi itu (Sugiyono, 2012). Sampel yang dilibatkan dalam penelitian ini adalah para pengunjung lokasi penelitian, para pelaku wisata, organisasi wisata dan Kepala Bidang Pemasaran dan Promosi Usaha Pariwisata, Dinas Kebudayaan dan Pariwisata.

Data yang digunakan pada penelitian ini adalah kombinasi dari data primer dan data sekunder. Data primer diperoleh melalui kuisioner, yang berisi seperangkat pertanyaan atau pernyataan tertulis kepada responden untuk dijawab (Sugiyono, 2012). Variabel Penelitian pada penelitian ini yaitu social media (variabel X) sebagai variabel independen dan Brand Awareness sebagai variabel dependen (variabel Y). Variabel independen terdiri dari $\mathrm{X}_{1}$ (Youtube), $\mathrm{X}_{2}$ (Facebook), $\mathrm{X}_{3}$ (Instagram), dan $\mathrm{X}_{4}$ (Twitter).

Analisis data pada penelitian ini bersifat kuantitatif/statistik dengan tujuan untuk menguji hipotesis yang telah ditetapkan. Teknik analisis data yang digunakan oleh peneliti yaitu menggunakan metode statistik regresi linear berganda. Analisis regresi berganda digunakan oleh peneliti untuk meramalkan bagaimana pengaruh dari social media (youtube, facebook, instagram, dan twitter) terhadap brand awareness pariwisata berbasis swadaya masyarakat di Kota Batam.

\section{HASIL PENELITIAN DAN PEMBAHASAN}

Analisis data dalam penelitian ini menggunakan analisis regresi berganda. Variabel Penelitian pada penelitian ini yaitu social media (variabel X) sebagai variabel independen dan Brand Awareness sebagai variabel dependen (variabel Y). Variabel independen terdiri dari $\mathrm{X}_{1}$ (Youtube), $\mathrm{X}_{2}$ (Facebook), $\mathrm{X}_{3}$ (Instagram), dan $\mathrm{X}_{4}$ (Twitter). Adapun rumus dari regresi berganda adalah $\mathrm{Y}=\mathrm{a}+\mathrm{b} 1 \mathrm{X} 1+\mathrm{b} 2 \mathrm{X} 2+\mathrm{b} 3 \mathrm{X} 3+\mathrm{b} 4 \mathrm{X} 4$ Dari hasil analisa data primer, diperoleh hasil sebagai berikut:

Tabel 4 : Uji Analisis Regresi Linier Berganda

\begin{tabular}{cccc}
\hline Model & \multicolumn{2}{c}{ Unstandardized Coefficients } & \multicolumn{2}{c}{ Standardized Coefficients } \\
& $\mathrm{B}$ & Std. Error & Beta \\
\hline Constant & 1.390 & .300 & .752 \\
X1 & .500 & .093 & .602 \\
X2 & .400 & .058 & .555 \\
X3 & .399 & .063 & .416 \\
X4 & .333 & .001 & \\
\hline
\end{tabular}


Berdasarkan perhitungan yang dilakukan menggunakan SPSS diatas akan didapat persamaan regresi berganda model regresi sebagai berikut: $\mathrm{Y}=1,390+0,50$ $\mathrm{X} 1+0,40 \mathrm{X} 2+0,399 \mathrm{X} 3+0,333 \mathrm{X} 4$.

Berdasarkan persamaan regresi tersebut dianalisis pengaruh media sosial terhadap brand awarenss yaitu : 1) variabel Youtube (X1) berpengaruh positif dengan Brand Awareness, 2) variabel Facebook (X2) berpengaruh positif dengan Brand Awareness, 3) variabel Instagram (X3) berpengaruh positif dengan Brand Awareness, 4) variabel Twitter (X4) berpengaruh positif dengan Brand Awareness.

Berdasarkan hasil uji F di dapat nilai Fhitung > Ftabel kemudian dilihat dengan hasil nilai probabilitas signifikan $0,000<0,05$ maka Ho ditolak dan Ha diterima. Dari nilai tersebut maka dapat disimpulkan bahwa media sosial youtube, Facebook, Instagram, dan Twitter, berpengaruh secara signifikan terhadap Brand Awareness pariwisata berbasis swadaya masyarakat.

Tabel 5 : Kesimpulan Model

\begin{tabular}{lrrrr}
\hline Model & R & R Square & Adjusted R Square & Std. Error of the Estimate \\
\hline 1 & $.752^{\mathrm{a}}$ & .566 & .546 & .52842
\end{tabular}

\footnotetext{
a. Predictors: (Constant), x1, x2, x3, x4

b. Dependent Variable: y
}

Dari data diatas, hasil dari proses yang menggunakan SPSS sebagai perhitungan, maka besarnya nilai $\mathrm{R}$ Square sebesar 0,566 atau 56,6\%. Interpretasinya adalah pengaruh yang ditimbulkan sosial media youtube, facebook, Instagram, twitter sebesar 56,6\% terhadap Brand Awareness pariwisata. Sisanya yaitu 43,4\% dipengaruhi oleh variabel lain yang tidak terangkum dalam penelitian ini. Dengan demikian dapat disimpulkan bahwa variabel media sosial berpengaruh positif dan signifikan terhadap Brand Awareness pemasaran pariwisata berbasis ekonomi masyarakat.

\section{E. PENUTUP}

Destinasi Pariwisata adalah area atau kawasan geografis yang berbeda dalam satu atau lebih wilayah administratif yang di dalamnya terdapat unsur: daya tarik wisata, fasilitas pariwisata, aksesibilitas, masyarakat serta wisatawan yang saling terkait dan elengkapi untuk terwujudnya kegiatan kepariwisataan. Dengan adanya pemasaran objek wisata yang dikelola secara swadaya masyarakat dengan menggunakan media sosial, diharapkan dapat meningkatkan kesadaran masyarakat untuk menggarap wisatawan local dengan menggunakan branding "visit our own country".

Karena itu disarankan kepada pihak-pihak yang terkait dengan pengembangan pariwisata di kota Batam agar membangun citra pariwisata Batam untuk rencana jangka panjang melalui Corporate Identity. Selain itu, perlu kegiatan pemasaran objek wisata melalui promosi wisata baik ke dalam dan luar negeri yang dilakukan secara terarah, terencana dan terpadu dengan memanfaatkan secara optimal kerjasama kepariwisataan regional dan global sehingga dapat terwujudnya Batam sebagai kawasan pengembangan budaya bangsa dan menjadi pintu gerbang pariwisata bagian barat.

Penelitian ini terbatas hanya pada lingkup pariwisata kota Batam, peneliti selanjutnya dapat menggunakan pendekatan lainnya untuk pengembangan pariwisata Indonesia untuk jangka panjang. 


\section{DAFTAR PUSTAKA}

APJII. (2016). No Title. Retrieved December 19, 2018, from https://www.apjii.or.id/downfile/downloadsurvei/infografis_apjii.pdf

Arisandi, D. (2017). The Influence Of Humor Appeals to Brand Awareness in Television Advertisement. Jurnal Ilmiah Manajemen \& Bisnis, 18(1), 1-8.

BPS Kota Batam. (2015). No Title. Retrieved December 19, 2018, from https://batamkota.bps.go.id/statictable/2015/12/17/49/tingkat-penghunian-kamarhotel-berbintang-menurut-klasifikasi-bintang-2014.html

BPS Kota Batam. (2017a). No Title. Retrieved December 19, 2018, from https://batamkota.bps.go.id/statictable/2018/11/07/69/banyaknya-wisman-jiwayang-datang-melalui-pintu-masuk-batam-dan-pertumbuhannya-persen-20102017.html

BPS Kota Batam. (2017b). No Title. Retrieved December 19, 2018, from https://batamkota.bps.go.id/dynamictable/2017/10/03/23/penduduk-kota-batammenurut-kecamatan-dan-jenis-kelamin-2011-2016.html

Constantinos Iacovou. (2016). An Analysis of Social Media Marketing Strategies and Best Practices of Hospitality and Tourism Organizations. Prescott Valley.

Dewi, Luh Komang Candra; Wisnawa, I Made Bayu; Prayogi, P. A. (2015). Positioning Pengembangan Daya Tarik Wisata Kabupaten Tabanan Menjadi Destinasi Kreatif dan Berkelanjutan. Jurnal Bisnis Dan Kewirausahaan, 11(2), 126-134.

Disbudpar Kota Batam. (2016). Pengembangan Pariwisata Kota Batam. Batam.

Hays, S., Page, S. J., \& Buhalis, D. (2013). Social media as a destination marketing tool: its use by national tourism organisations. Current Issues in Tourism. https://doi.org/10.1080/13683500.2012.662215

Rossiter, J. R., \& Percy, L. (1987). Advertising and Promotion Management. New York: Mc-Graw Hill International.

Sembiring, J. P. (2016). Strategi Komunikasi Pemasaran Objek Wisata Gundaling dan Pemandian Air Panas Semangat Gunung. Jurnal Simbolika, 2(1).

Social, W. A. (2017). No Title.

Stokes, R. C. (1985). The Effects of Price, Package Design, and Brand Familiarity on Perceived Quality. In Perceived Quality (pp. 233-246). Toronto: Lexington Books.

Sugiyono. (2012). Memahami Penelitian Kualitatif. Bandung: Alfabeta. 